Revista Monografias Ambientais

Santa Maria, v. 14, n. 2, mai-ago 2015, p. 01-12

Revista do Centro de Ciências Naturais e Exatas - UFSM

ISSN : 2236-1308

\title{
Relação Ser Humano e Natureza: Um Desafio Ecológico e Filosófico
}

Relationship between human beings and nature: An ecological and philosophical challenge

Keila Camila da Silva ${ }^{1}$, Yanina Micaela Sammarco ${ }^{2}$

${ }^{1}$ Mestranda em Ciências da Engenharia Ambiental, Centro de Recursos Hídricos e Ecologia Aplicada, Universidade de São Paulo, São Carlos, SP, Brasil

${ }^{2}$ Doutora em Educação Ambiental, Universidade Federal do Paraná, Curitiba, PR, Brasil

\section{Resumo}

As questões socioambientais tem sido motivo de muitas discussões e reflexões devido à crise ambiental. Diversos estudos demonstram que uma relação mais estreita existente entre ser humano e a natureza vem se perdendo ao longo do passar dos anos. Nesse cenário, torna-se cada vez mais importante estudar as percepções e atitudes ambientais para a construção de uma sociedade, que resgate os valores e o respeito pelo seu ambiente. A educação ambiental surge, neste contexto como uma ferramenta na busca pela sensibilização para tais percepções e atitudes.

Palavras-chave: Educação Ambiental. Ser humano e natureza. Percepção ambiental.

\begin{abstract}
Social and environmental issues has been the subject of many discussions and reflections due to the environmental crisis. Several studies show that a closer relationship between humans and nature has been lost over the passing years. In this scenario, more and more important it is to study the perceptions and attitudes toward the environment for the construction of a society that rescue values and respect for their environment. Environmental education emerges in this context as a tool in the search for awareness of such perceptions and atitudes.
\end{abstract}

Keywords: Environmental Education. Human and nature. Environmental perception. 


\section{Introdução}

A relação humana com seu ambiente natural mostra-se ser predominantemente capitalista na sociedade moderna. Com as concepções adotadas já a algum tempo e atualmente, percebe-se o ser humano cada vez mais como o centro do mundo, trazendo como consequência desastres em esferas globais devido ao seu exacerbado domínio sobre o ambiente natural.

Isto é, com a evolução cada vez mais acelerada da espécie, o ser humano adquiriu muitas habilidades e conheceu novos avanços científicos em prol de seu benefício, porém causou desequilíbrios no ambiente em que vive. No entanto, nos perguntamos: seria errado retirar da natureza aquilo que ela tem a nos oferecer? Não, à medida que o planeta suporte e consiga se recompor, porém muitas espécies estão desaparecendo, florestas estão deixando de existir, lagos estão secando e cada vez mais são apresentadas notícias de desastres relacionados ás questões ambientais, principalmente no meio urbano.

Essa postura deveria ser modificada, na qual o ser humano passe a ter uma relação harmônica com a natureza, passando a viver de forma mais sustentável. Muitos estudos são realizados com a ideia de sensibilizar a sociedade, mas nem sempre são capazes de surtir os efeitos desejados. Com isso surgem a educação e a percepção ambiental como uma forma de aproximação. Porém, nota-se que ainda faltam muitos esforços para a valorização humana com a natureza. Nesse contexto, o objetivo desse trabalho foi fomentar a relação humana com o ambiente natural, buscando uma reflexão ecológica e filosófica acerca da mesma, através de um estudo de caso abordando a percepção ambiental no Bosque Campos Prado, localizado no município de Jaú, São Paulo.

\section{A psicologia e o ambiente}

Estudar o ambiente, requer conhecer tanto fatores abióticos como os bióticos do meio. Como abióticos pode-se entender o conjunto de influências ambientais a que os organismos estão sujeitos, físicos, químicos e biológicos, como a luz, a temperatura, etc. E bióticos, são todos os organismos vivos presentes. Porém é importante ressaltar que nem um é menos importante que o outro. Ao se falar estritamente na relação ser humano e natureza, surgem diversas áreas com fins de estudar o seu interrelacionamento.

O homem já deixou de ser mero aspecto da biogeografia (simples unidade de um ecossistema), para se tornar cada vez mais um elemento afastado do meio físico e biológico em que vive. Quando se tornar capaz de fabricar ou 
sintetizar alimentos de matérias inorgânicas - perspectiva que não é improvável -, um vínculo basilar, o do homem com a terra viva, estará rompido. (DREW, 1994).

O planeta Terra está chegando a condição de se tornar impróprio para a vida humana, animal e vegetal a partir do modelo de produção e exploração dos recursos naturais dos últimos séculos. Nesse sentido, é importante entender como se estabelecem as relações humanas com o ambiente, estas que muitas vezes colocam em risco o futuro da humanidade. Por esse motivo, as perspectivas de transformação social veem trazendo estímulos a estudos interdisciplinares com a Psicologia Ambiental.

Estudar o ser humano no contexto físico e social pode ser notado em várias disciplinas, mas suas interrelações com o ambiente, mais necessariamente, as percepções, atitudes e comportamentos em relação ao ambiente natural, veem sendo analisada pela psicologia ambiental. Compreende-se que tanto o ambiente como o próprio ser humano sofrem influências e são influenciados um pelo outro. As interações humanas com seu ambiente natural são complexas, e vários comportamentos são identificados à medida que essas relações ocorrem, sendo estas individuais e coletivas para com o entorno em que vivem.

A Psicologia Ambiental como análise qualitativa, representa uma entrada a dimensões pouco acessíveis para os estudos quantitativos, permitindo assim compreender melhor as atitudes, crenças, motivações e comportamentos do grupo que se pretende estudar.

A exploração do ambiente, "um sistema comportamental que capacita o indivíduo a interagir com o ambiente, a adquirir informação e construir sistemas de conhecimento" (KELLER, 1998), acarreta não apenas o adensamento populacional, como também alterações no modo de relacionamentos interpessoais e ambientais.

Mudanças ambientais sempre ocorreram no planeta, ao longo do tempo, porém todas derivadas de causas naturais, e onde a natureza era utilizada pelos seres humanos e animais, apenas para satisfação das necessidades, o que favorecia o ciclo natural.

A partir do momento em que o ser humano deixou de ser parte constituinte desse ambiente e passou a agir como dono, devido às descobertas e avanços tecnológicos, trouxe também impactos que fizeram com que a utilização dos bens naturais, visando cada vez mais consumo e aumento da economia, fossem maiores do que a capacidade do planeta em recompor. Pode-se considerar que a humanidade, está ameaçada pelos padrões da sociedade: “Os padrões tecnológicos e o modelo predador de crescimento, que maximizam as ganâncias econômicas em curto prazo, revertendo os custos sobre os sistemas naturais e sociais" (LEFF, 1999).

Touraine (1985) criou o termo "sociedade programada" para nomear a sociedade com características de ciência e tecnologias, individualização, crise ambiental, visando a emergência para 
mudanças na dinâmica social. Nesse contexto, Castro (1998) entende que deve haver maior relevância a sociedade, que são os principais responsáveis pela situação ambiental, com a busca de um novo modelo que requer a junção entre atitudes e práticas sociais.

As extensas zonas urbanas, as regiões densamente povoadas criam um ambiente artificial cheio de voracidade, a demandar sempre maior quantidade de recursos naturais para moradia, a alimentação, o vestuário, o trabalho e a produção, o recreio e a locomoção, para aquela cadeia interminável das atividades humanas. (COIMBRA, 1985).

\subsection{Ser humano e ou (versus) natureza?}

Com o decorrer dos anos, cada vez mais despertou-se o interesse pela relação dos seres com seu ambiente, mais especificadamente a relação humana, a qual vem trazendo diversos conflitos na sociedade.

Todos os organismos vivos se interrelacionam e interdependem. O que diferencia os seres humanos dos vegetais e animais é sua racionalidade, ou seja, "o ser humano é construído no tempo", pois vive no passado e no futuro, como no presente, sendo capaz de produzir uma ordem social. Ao longo do tempo, modifica o ambiente para satisfação de suas necessidades, cada vez maiores.

Cada indivíduo percebe, reage e responde diferentemente frente às ações sobre o meio. As respostas ou manifestações são, portanto, resultado das percepções, dos processos cognitivos, julgamentos e expectativas de cada indivíduo. Embora nem todas as manifestações psicológicas sejam evidentes, são constantes, e afetam nossa conduta, na maioria das vezes, inconscientemente. (FAGGIONATO, 2011).

De acordo com Tuan (2012), a tarefa de estabelecer ligações entre ser humano e natureza é complexa, porque envolve a subjetividade humana, porém sabe-se que atitudes, valores e percepções não poder ser excluídas. Estudando como os seres humanos percebem seu mundo, como a cultura influencia, o significado da cidade e do ambiente, podem ser auxiliados através de pesquisas, questionários e entrevistas, contribuindo para a psicologia ambiental.

A humanidade nunca existiu isolada do resto da vida, e não poderia existir sozinha, pois ela depende das associações complexas e íntimas que tornam a vida possível (HOEFFEL, MACHADO, SORRENTINO, 2008).

Sentimentos de desligamento e paz, são encontrados pelos seres humanos quando em contato com o ambiente natural que normalmente lhes remete vivências e se percebe como a paisagem mudou com o tempo, porém todos os sentidos são importantes para que o mesmo se envolva com o local. Transformar ideias em uma sociedade envolve o conhecimento e participação de todos. A partir dos 
avanços tecnológicos e científicos e sua apropriação por estruturas sociais de poder, vemos que vida humana está cada vez mais próxima da techne e cada vez mais longe da physis (SAMMARCO, 2005).

A reflexão acerca das relações humanas com o ambiente nos remete as questões ambientais atuais. Filosoficamente, a relação humana com o ambiente pode ser pensada sobre outro ponto, quando definida que a própria condição humana é natural. O ser humano, em sua essência, é natural, assim como todos os outros seres, o que os difere é sua capacidade de racionalização, ou seja, é dotado de uma consciência intencional.

Os filósofos da antiguidade se interessavam pelos processos da natureza que originavam todas as coisas vivas e não vivas. Observavam transformações na mesma, mas se perguntavam como essas seriam possíveis. Derivada do pensamento humano: "quem somos, de onde viemos e para onde vamos? " a filosofia permitiu muitos questionamentos em relação a toda base existencial humana, inclusive a relação com a natureza, pois o ser humano sempre buscou sua natureza na filosofia:

Estudar o ser humano é um desafio. Mesmo que cada um de nós passasse horas na frente de um espelho, por vários dias, a cada hora e a cada dia veríamos muitas imagens diferentes de nós mesmos. O mundo muda e nós também. Caracterizar uma natureza do ser humano é quase impossível, cada um de nós tem muitas naturezas dentro de si. Algumas conhecemos bem, outras serão eternamente um mistério. Conhecer os mistérios do outro é o que nos aproxima, é o que nos atrai ao nosso semelhante ou diferente. Conhecer o mistério do mundo é o que nos torna filosóficos e científicos. (SAMMARCO, 2005).

Com isso, uma visão, onde o ser humano está centrado no planeta como sua morada e parte de si, pode permitir o surgimento de um comportamento diferenciado em relação à natureza, onde o mesmo possa entender sua responsabilidade para com todos os seres vivos e com isso, surge a necessidade de uma nova conduta, uma nova concepção filosófica ser humano-natureza. Sua base científica engloba neste binômio todas as raças humanas e todos os seres existentes, abrangendo também os inanimados.

\section{Percepção e educação ambiental em Jaú - SP}

Devido ao grande confronto de ideias que hoje percorrem na mente humana, o ser humano vem esquecendo algumas emoções, e perdendo o sentimento de pertencer ao meio ambiente que conhecia para agora dar espaço a um meio ambiente materializado. (SILVA, 2011). Pilotto (1997) afirma que a percepção ambiental é, pois, a experiência sensitiva mais direta e imediata do meio ambiente, e, ainda que afetada pela memória e cognição, é muito independente. Atualmente é fundamental o estudo da percepção do meio ambiente na e para a Educação Ambiental, ou seja, como 
parte do processo de formação de conhecimentos e, consequentemente, do sistema de valores. (SAMMARCO, 2005).

A percepção ambiental surgiu como uma forma da busca de conscientização pelo ambiente, buscando na condição humana o olhar para o mundo: a Terra é o lar de todos os seres vivos.

A Educação Ambiental visa à construção de relações sociais, econômicas e culturais capazes de respeitar e incorporar as diferenças (minorias étnicas, populações tradicionais), a perspectiva da mulher, e a liberdade para decidir caminhos alternativos de desenvolvimento sustentável respeitando os limites dos ecossistemas, substrato de nossa própria possibilidade de sobrevivência como espécie. (MEDINA, 1999).

O rápido crescimento urbano e as consequentes alterações na paisagem e das características ambientais, principalmente nas cidades, têm gerado uma série de problemas ambientais afetando a qualidade de vida de suas populações (CAVALHEIRO; DEL PICCHIA, 1992). De tempos em tempos, o nosso Planeta Terra nos diz alguma coisa. Hoje estamos sentindo os problemas que resultaram de muitos e muitos anos de agressão ao ambiente, em nome do progresso. (PALMA, 2005).

Nesse contexto, em que se estuda a educação ambiental, buscou-se identificar a percepção ambiental no município de Jaú, São Paulo, mais especificamente, em relação ao Bosque Campos Prado. O estudo baseou-se na percepção ambiental de 35 moradores dos bairros considerados de entorno do Bosque: Jardim Campos Prado, Vila São Judas Tadeu, Vila Netinho Prado, Vila Maria e Jardim Maria Cibele, através da técnica de entrevista semiestruturada. A técnica utilizada para aplicação das entrevistas com professores foi o estudo através do grupo focal, caracterizado por envolver um pequeno grupo de pessoas que discutem conceitos. O grupo foi composto por 17 professores nas duas escolas. Foram realizados também, 24 desenhos com alunos das escolas, através da técnica de mapa mental, que visa trazer à tona lembranças e memórias relacionadas a um certo tema. Os alunos foram escolhidos com base aqueles que moram nos bairros considerados de entorno do Bosque. Alguns aspectos foram levados em consideração para melhor obtenção dos dados: a-) procurou-se abranger um pouco de cada Bairro, através de um número equilibrado de entrevistas por bairro. b-) com os professores procurou-se abranger também várias disciplinas. c-) com os alunos procurou-se abranger todos os bairros de estudo.

\subsection{O Bosque}

O Bosque Campos é uma área verde municipal e está localizado no Jardim Campos Prado. Faz parte da história da cidade de Jaú, é uma área passada de geração em geração pela família Campos Prado, considerada da alta sociedade e da qual originou seu nome. Durante muitos anos a família lutou pela conservação da área do Bosque, então foi em 1995, que o Senhor Luiz de Campos Prado que 
na época era o proprietário da área, resolveu doar esse remanescente para a Prefeitura Municipal de Jaú, considerando como área verde do Jardim Campos Prado I e pensando que assim diminuíssem os problemas ambientais causados pela ação humana. Com o passar do tempo o Bosque Campos Prado continuou sofrendo com os problemas antrópicos que existiam, e aumentou com o vandalismo de alguns jovens que invadiam a área para praticar atos de pichações, magia negra e uso de drogas, que acabam interferindo na área também. Ao notar que a Prefeitura não estava em condições de defender o Bosque daqueles problemas, em 1988 o proprietário adotou a área e tornou-se um de seus protetores.

\subsection{Diálogo com moradores, professores e alunos}

A entrevista com os moradores dos bairros de entorno do bosque e com professores, demonstraram que a maioria da população entrevistada considera áreas verdes como locais onde existe a presença de árvores e plantas, sendo considerados elementos representativos. Ao se questionar os moradores se os mesmos conheciam o bosque, $68,6 \%$ responderam que sim e $31,4 \%$ responderam que não, porém quanto a já ter o visitado observou-se que a maioria, 85,7\% nunca visitou enquanto apenas 14,3\% já esteve no local. Quanto aos professores, 58,8\% relataram conhecer o bosque, enquanto $41,2 \%$ não o conheciam. Esses dados demonstram que a população, apesar possuir conhecimento da existência do Bosque, a maioria nunca o visitou. Com isso, as percepções demonstraram que o ser humano vem se afastando cada vez mais do meio em que vive, demonstrando um elo rompido.

Quando se perguntou aos moradores onde costumam passar suas horas de lazer, notou-se que eles gostam do contato com a natureza, mas que a falta de tempo faz com que não se mantenham por muito tempo. Os moradores também consideram que morar próximos ao bosque traz influências positivas em suas vidas (54,3\%) enquanto outros $45,7 \%$ considera que não há essa influência. Nesse sentido, entende-se que a sociedade atual em que vivemos, com características meramente tecnológica, trouxe consigo maior relevância ao "ter" do que o "ser", onde o modelo de desenvolvimento aderido pela cultura, mas quando observamos tudo que nos cerca, percebemos que existe algo imenso e que abriga todas as formas de vida, inclusive nós humanos, porém todos temos papéis fundamentais nesse ambiente. Como seres racionais, criamos uma "segunda natureza", a qual orienta os aspectos importantes da vida humana, ou também conhecida como cultura. Desta, somos influenciados pelos valores, assim como os criamos.

Outra questão abordada na pesquisa foi sobre o investimento em áreas verdes, onde comprovou-se que a grande maioria $(60 \%)$ não consideram que haja investimentos suficientes, enquanto $47 \%$ dos professores também consideraram a falta de investimentos. Frente a isso, a falta de 
interesse pelo setor público na preservação e conservação de áreas naturais no meio urbano, serve como incentivo para que a própria população também não se preocupe e dê seu devido valor. A vida é complexa, e existe na natureza um ser que é o mais complexo de todos: o humano, o qual trouxe para a mesma todas suas complexidades e necessidades até superiores das quais ela é capaz de propiciar.

Quanto ao contato humano com a natureza, observa-se que a população considera que existe um grande distanciamento entre ambos, 97,1\% dos entrevistados consideraram que a perda é evidente, enquanto apenas 2,9\% consideram que não há a perda do contato. Para os professores, observou-se que $88,2 \%$ consideram também a perda do contato, enquanto $11.8 \%$ não a consideram. Esse fato demonstra a necessidade de políticas e estudos educacionais que visem a sensibilização das pessoas. Antes de falar sobre a relação humana com a natureza, precisamos entender quem é o "ser humano". Ser humano é complexo, por isso sua natureza é difícil de se compreender, e como posição racional somos assumidos como elemento diferenciador da realidade em que vivemos.

Como enfatiza Tuan (2012): “Uma perspectiva humanista da ciência e do ambiente está longe de ser parte do pensamento dominante. Continuamos com uma visão funcionalista da relação ser humano e ambiente, que prioriza o ter ao ser na discussão ambiental, valorizando mais a perspectiva econômica do que a existencial". Ainda segundo Tuan (2012), os antigos viam o movimento da natureza em um trajeto circular que representava a perfeição, os modernos, postulam a linha reta como o trajeto, sugerindo que não há mais a perfeição natural, devido ao contato humano com o natural.

“Quando buscamos compreender algo que é exterior a nós, podemos agir com maior distanciamento, mas, como no caso da natureza, é preciso que percebamos nossa inevitável ligação com ela." (ROBLE, 2012). Somos produtos da natureza que nos cerca, ao mesmo tempo em que, pela racionalidade, transformamos esse todo natural, porém, entre todos os seres vivos, de certo, o ser humano é aquele capaz de interferir em sua totalidade, inclusive de modo consciente.

Indagou-se também sobre as lembranças e memórias que os moradores possuem em áreas verdes, onde $80 \%$ dos moradores relembraram fatos junto a natureza, enquanto $82,4 \%$ dos professores também relembraram. Aqui, pelas percepções, novamente se observa que a população gosta do contato com o meio natural, mas esse contato está escasso na sociedade, principalmente devido ao modo de vida, que faz com que as cidades se tornem cada vez mais locais caracterizados pelo asfalto e não pelo verde.

Os professores também relataram, que em sua maioria, nunca pensaram em realizar atividades extraclasse com os alunos no bosque, a maioria $(88,2 \%)$, pela falta de conhecimento do local, porém em outras áreas verdes, $58,8 \%$ já pensou em levar os alunos. Também observou-se que $76,5 \%$ dos professores relacionam assuntos da temática ambiental em suas aulas. A questão ambiental, 
deve ser fortificada nas relações humanas, desde a pequena idade. A modernidade representou mudanças no modo do ser humano agir com a realidade, muitas formas de relação foram perdidas, dando lugar às mudanças, mas as pequenas relações devem ser preservadas, para que não sejam totalmente esquecidas e perdidas.

Quanto aos alunos, realizou-se os mapas mentais, com o objetivo de conhecer o que os alunos mais observam em seus bairros e saber assim, se o Bosque Campos Prado seria alvo dos desenhos. Pelos desenhos, observou-se que praticamente todos representaram árvores, casas e ruas. Ao término dos desenhos, foi possível notar que a maioria dos alunos (87,5\%) não desenharam o bosque. Podemos observar que apesar de morar próximos ao mesmo, muitas dessas crianças não percebem ou não sabem que existe o Bosque.

Após isso, pediu-se que os alunos utilizassem uma caneta azul e desenhassem as áreas verdes presentes em seu bairro. Notou-se que apenas 33,3\% dos alunos desenharam áreas verdes. Observouse que as crianças não possuem pertencimento com o Bosque em si, porém possuem pertencimento pelas árvores, casas, ruas, e outras áreas verdes, onde podem ao mesmo tempo estar ao ar livre e brincar.

"Aqueles que vivem próximos, pensam próximo" devido a cultura. Claro que cada pessoa possui sua singularidade e não existem duas pessoas idênticas, mas vê-se o resultado da expressão cultural. De acordo com Geertz (1989) o ser humano está amarrado a teia de significados que ele próprio teceu.

\section{Conclusões e Considerações Finais}

Tanto o indivíduo como o grupo, apesar das diferenças, como mesma espécie estão limitados a ver as coisas de uma certa maneira. Seres humanos compartilham percepções em comum, mas duas pessoas não veem a mesma realidade, não pensam igual, nem avaliam o ambiente da mesma maneira.

Ao se falar em área verde, as pessoas logo imaginaram árvores como o elemento representativo da paisagem. Também podemos ver que não lembram de comentar sobre o Bosque Campos Prado mesmo estando perto deles. As pessoas entrevistadas possuíam grande interesse em relação ao meio ambiente, porém não sabiam uma forma de se aproximar do mesmo, sem que haja incentivos.

A percepção ambiental serve como "arma de defesa" do meio ambiente visando reaproximar o ser humano da natureza, para que o mesmo seja preservado para as próximas gerações e buscando o respeito. "O futuro da humanidade continua promissor se ela tiver a sabedoria de enfrentar os problemas" (ASSMANN, 2000). 
Assuntos relacionados às áreas verdes são de pouco conhecimento, até para aquelas pessoas que residem próximas as mesmas. Ainda com relação ao Bosque Campos Prado, podemos ver que apesar de ser um local conhecido, é pouco visitado, um dos fatos disso se deve pela população pensar que o Bosque ainda é uma propriedade privada, sendo que é considerado como área verde do Jardim Campos Prado, e também pelo fato do ser humano não se importar muito com o ambiente, ou seja, não possui interesse no assunto natureza.

Com base no Bosque, pode-se ver que ao se falar sobre ele, as pessoas costumam buscar o pertencimento dentro delas, que estava guardado. Começam a lembrar de vivências e de que o meio ambiente deve ser cuidado. Por falta de investimento em áreas verdes, as pessoas também acabam não se importando, assim como no Bosque Campos Prado, que ficou muito tempo fechado, sem ser aberto para visitação e desconhecido até para os moradores próximos a ele. Agora, em relação às crianças: Ann Skantze apud Bleger (1984) aponta, em seu estudo sobre como as crianças experienciam os lugares urbanos, para a preferência de lugares que permitem e inspiram aventura, excitamento e imaginação, em que as impressões sensoriais e atmosfera dos lugares são importantes, como sendo os esquecidos pelos adultos.

O atual modelo de civilização, totalmente desvinculado do ambiente, mostra a dificuldade na percepção e de atitudes conservadoras, devido ao distanciamento e o desconhecimento. A partir do momento que se toma conhecimento sobre o ambiente, é possível respeitá-lo. Para que se possa perceber, é preciso que exista interesse no objeto de percepção, e isso se dá através do conhecimento do mesmo, da cultura, do valor e da ética, por isso varia de pessoa para pessoa. Como no caso do meio ambiente, cada pessoa possui uma percepção diferente.

Nesse sentido, da relação que se forma entre ser humano e natureza ao longo do tempo, com a educação ambiental, são tecidas reflexões e mudanças no que tange ao ambiente. Atualmente é possível observar a (re)educação para formação de cidadãos conscientes e que buscam tecer novos laços socioambientais. "Somos parte de um equilíbrio natural e dependemos desse equilíbrio para a manutenção de nossa vida" (ROBLE, 2012).

Inseridos nessa natureza, o ser humano se faz presente, criando sua cultura. Essa cultura fez com que os mesmos abdicassem de sua condição natural, adquirindo significados, hábitos, condutas e valores. Dessa forma, a vida em sociedade preconiza o viver em conjunto, partilhando de tais valores. Esse viver em sociedade revela as marcas deixadas na natureza.

“A cultura é corresponsável pela nossa natureza. Isso não significa dizer que os fatores biológicos são irrelevantes. " (ROBLE, 2012). Temos uma parte de nós que responde a partir da condição natural e outra parte a cultural. Não há como isolar o ser humano dessas teias e analisa-lo sem a cultura, como um ser natural, a cultura está indissociável do mesmo e é isso que o torna efetivamente humano. Ser humano se completa na sociedade. 
Estudar a relação humana com a natureza é um desafio, pois tanto ecológica e filosoficamente, vemos diversas mudanças nessa forma de relacionamento, com a construção de vastos sistemas filosóficos, mitos e religiões, entrelaçados a uma crise de valores. Será que todos os questionamentos atuais poderiam ajudar a lidar com os problemas práticos do mundo real? Pois toda essa crise ambiental possui consequências que são compartilhadas por todos e condenam a natureza. "E se a consciência de nossas verdadeiras relações com os restantes seres vivos contribuir para o abandono da noção de propriedade da natureza, então sentir-se parente do pássaro que canta em sua janela não vai ser só uma sensação maravilhosa. Vai também ajudar a fazer o mundo melhor". (FERNANDEZ, 2009).

\section{Referências Bibliográficas}

ASSMANN, H.; SUNG, J. M. Competência e sensibilidade solidária: educar para a esperança. Petrópolis: Vozes, 2000.

BLEGER, J. Psicologia da conduta. 1984, 242p.

CASTRO, R. Educacíon ambiental. Capítulo 15 em: Psicología Ambiental. J. I. Aragonés e Amperico. Ed. Psicología Pirámide, 1998.

CAVALHEIRO, F.; DEL PICCHIA, P.C.D. Áreas Verdes: conceitos, objetivos e diretrizes para o planejamento. In: Congresso Brasileiro sobre Arborização Urbana. Anais... Vitória: PMV, 1992. p. 2938.

COIMBRA, J. A. A. O outro lado do meio ambiente. São Paulo: CETESB, 1985. 204 p.

DREW, D. Processos Interativos Homem-Meio Ambiente/David Drew; tradução de João Alves dos Santos: revisão de Suely Bastos; coordenação editorial de Antonio Christofoletti. - $3^{\mathrm{a}}$ Ed. - Rio de Janeiro: Bertrand Brasil, 1994, 201 p.

FAGGIONATO, S. Percepção Ambiental. Disponível em

$<$ http://educar.sc.usp.br/biologia/textos/m_a_txt4.html> Acesso em: 15 de Agosto de

2011.

FERNANDEZ, F. O poema imperfeito: crônicas de biologia, conservação da natureza e seus heróis. Curitiba, PR: Ed. UFPr, 2009.

GEERTZ, C. A interpretação das culturas. Rio de Janeiro: Guanabara Koogan, 1989. 15p.

HOEFFEL, J.L; FADINI, A.A.B. "Percepção Ambiental". In: Encontros e Caminhos: Formação de Educadoras (es) Ambientais e Coletivos Educadores. 2o volume. Brasília. 2007, 357p.

KELLER, H. Exploratory behavior, place attachment, genius loci, and childhood concepts: Elements of understanding children's interactions with their environments. Berlin: Walther de Gruyter. p. 454-468.

LEE, S. Amazing Fantasy 15. New York: Marvel Comics, 1962.

LEFF, E. Educação ambiental e desenvolvimento sustentável. In: REIGOTA, M. (org.). VerdeCotidiano: o meio ambiente em discussão. Rio de Janeiro, DP\&A Editora, 1999.

MEDINA, Naná M. Formação de Multiplicadores para Educação Ambiental. In Revista Eletrônica do Mestrado em Educação Ambiental - FURG. Vol. 1., Out. - Dez/. 16 págs. 1999.

MELLAZO, G.C. A percepção ambiental e educação ambiental: uma reflexão sobre as relações interpessoais e ambientais no espaço urbano. Olhares \& Trilhas . Uberlândia, Ano VI, n. 6, p. 45-51, 2005.

PALMA, I. R. Análise da Percepção Ambiental como Instrumento ao Planejamento da Educação Ambiental. Porto Alegre, 2005.

ROBLE, O. Conhecimento da natureza, do homem e da sociedade. 1. Ed, ver. Curitiba: IESDE Brasil, 2012. 66p. 
SILVA, K. C. Pertencimento em Relação ao Bosque Campos Prado: Um Estudo de Percepção Ambiental da Comunidade do Entorno. 2011. (Graduação em Meio Ambiente e Recursos Hídricos) Faculdade de Tecnologia de Jahu, Jaú, 2011, 160p.

SAMMARCO, Y. M. Percepções Sócio-Ambientais em Unidades de Conservação: O Jardim de Lillith? .2005. 211p. (Mestrado em Engenharia Ambiental), Universidade Federal de Santa Catarina, Programa de Pós-Graduação em Engenharia Ambiental. Florianópolis. 2005, 211 p.

SATO, Michèle; SANTOS, J. E. "Tendências nas pesquisas em educação ambiental" in REIGOTA, M; NOAL, F.; BARCELOS, V. (Orgs.) Caminhos da educação ambiental. Santa Cruz do Sul: UDUNISC, 2001.

SMITH, R. L. Ecology. Encyclopedia Britannica: Macropedia, vol. 6. 1978.

TOURAINE, A. An introduction to the study of social movements. In: Social Research, no 52, 1985, p. 749 787. 